\title{
Prosperous yields forecasted with solidarity and commitment
}

\author{
Haemi Jee (D) https://orcid.org/0000-0002-9066-1472
}

A new year of 2019 has been launched. Since the establishment of the Journal of Exercise Rehabilitation (JER) in 2005, JER has been showing an exponential growth especially in recent years. JER has become literally a renowned international journal with its strong foundation in rehabilitation and exercise.

The year 2019 is a year of the year of fortune and luck according to the Eastern zodiac. The word 'Zodiac' is derived from the Latin word 'zodiacus' which means cycle or circle of animals. One of the main goals of the scientists regardless of the era has been to find a common pattern of certain phenomenon for prediction of the same occurrence before its initiation. Astrology was studied based on the same desire. Before the emergence of the modern scientific theories and findings, astrology was the only scientific approach for understanding the order of the nature. Bright minds of the ancient Bablylon, China, Hindu, or Roman eras have tried for solve their scientific curiosities through the celestial coordinate system. Although unscientific beliefs were derived, numerous modern scientific approaches have been obtained through astrology. Although 12 animals or signs of the Eastern or Western zodiac and supposed predictions of fortune and luck remains questionable, the occurrences of phenomena in circular or repeatable patterns seem very scientific. That is, the repeated occurrences of four seasons, 12 months, and 365 days per year can be guaranteed.

With the turn of the year, I, a proud member of the JER board, would like to take the blissful prediction of the Eastern zodiac in a blithe spirit on behalf of the JER board members. This blissful prediction for fortune and luck for the year of golden pig coincide with the progression of JER. However, it is not just pure zodiac that JER is on a role for fortune and luck. Although an opportunity knocks on everyone's door from time to time, only the prepared will be able to open the door to welcome the chance. The JER members persistently stayed and supported JER through thick and thin. The solidarity and commitment of the members and supporters have held up JER to grow and stand tall in a world of competitive science. JER has step by step reported the scientific community as a strong and stable platform to report the findings of rehabilitation and exercise science. With predicted fortune and luck, the year of 2019 will be another successful year to report JER to the world as an elite and prestigious leader in exercise rehabilitation.

\section{CONFLICT OF INTEREST}

No potential conflict of interest relevant to this article was reported.

Ethics Editor Department of Sports and Health Care, Namseoul University, 91 Daehak-ro, Seonghwan-eup, Sebuk-gu, Cheonan 31020, Korea E-mail: amyjee@nsu.ac.kr 